\title{
EXERCISE TESTING AFTER THE CHIARI PELVIC OSTEOTOMY
}

\author{
M. F. MACNICOL, HELEN UPRICHARD, G. P. MITCHELL \\ From the Princess Margaret Rose Orthopaedic Hospital, Edinburgh, Scotland
}

\begin{abstract}
The work capacity of 26 women after a Chiari pelvic osteotomy for symptomatic unilateral subluxation of the hip was assessed using two simple exercise tests: the maximal walking speed during a 12-minute test and the time taken to climb stairs. A significant linear decline in walking speed occurred with increasing age, despite the operation, and only one patient over the age of 25 years was able to walk at a normal rate. Compared to the results in a control group of women of similar age the stair climbing time was increased in 54 per cent of the patients and showed a significant negative correlation with the maximal walking speed. Age-adjusted walking speed was closely associated with the degree of pain experienced but there was no relationship between observed function and conventional clinical assessment based on the range of movement and the radiographic appearances of the hip.
\end{abstract}

The medial displacement pelvic osteotomy was introduced in 1955 by Chiari as one method of improving function in a hip with subluxation secondary to acetabular dysplasia. The principal indication for the operation is pain and in most instances this is partially, although seldom completely, relieved. Limp is rarely improve and may be increased. Hence the procedure is viewed as a salvage operation, delaying for some years the need for arthroplasty in a relatively youthful group of patients.

A number of authors have reviewed the clinical results and complications of the Chiari osteotomy (Kawamura 1959; Colton 1972; Chiari 1974; Hoffman, Simmons and Barrington 1974; Mitchell 1974; Salvati and Wilson 1974; Schulze and Krämer 1975; Lord and Samuel 1977; Chiari, Endler and Hackel 1978) and its indications have been discussed by Chapchal (1974).

In our opinion the operation is never indicated when reconstructive procedures such as the Salter osteotomy (Salter 1961, 1966) or the pericapsular iliac osteotomy (Pemberton 1965) are possible in the child. Chiari has, however, recently described his experience with the osteotomy in children as young as three years of age (Chiari and Schwagerl 1976).

This review does not seek to add to an already adequate literature of relatively short-term surgical results but will be confined to exploring the capacity for exercise of a small group of young women reviewed at least two years after a unilateral Chiari osteotomy undertaken for symptomatic subluxation of the hip. Correlations were sought between function and pain, age, a positive Trendelenburg sign, the range of movement, and the radiographic appearance. The validity of simple exercise tests in this context was examined and their results compared to the performance of a control group of normal women.

\section{CLINICAL MATERIAL}

Twenty-six female patients aged between 13 and 35 years (mean age 25 years) were compared to a group of 26 normal women of similar age (range 18-38 years, mean age 26 years). The patients had been handicapped by unilateral symptomatic subluxation of the hip and were reviewed on average seven years (range 2-12 years) after Chiari osteotomy. In eight patients mild, asymptomatic dysplasia was evident radiographically in the contralateral hip. None of the patients or control subjects suffered from pulmonary or cardiovascular disease, and no other joint symptoms were present. Clinical evaluation of the patients was carried out before and after operation but the exercise tests were confined to the postoperative period.

\section{METHODS}

Exercise capacity. This was assessed by two simple tests which have been described in detail elsewhere (Macnicol, McHardy and Chalmers 1980). The 12-minute test of maximal walking speed assessed both speed and stamina, thus giving an indication of aerobic work; pulse rate at the start and finish of the walk, stride length (the distance between consecutive heel strikes with the same foot) and cadence (steps per minute) were recorded. The stair climbing test gave an indication of anaerobic work, and had a linear relationship to the maximal walking speed (Macnicol et al. 1980). Time of ascent and the pulse rate at the start and finish of the climb were recorded. Results were expressed as the mean plus or minus the standard error of the mean (SEM).

Pain. After operation pain was classified into four grades: Grade 4-no pain or an occasional ache; Grade 3-slight pain but less than before operation. Grade 2-definite pain, with little change; and Grade 1 -pain made worse by the operation.

Age. The influence of age upon function was recognised by a simple grading of age which permitted walking speed to be correlated with pain and age. The grades for age were: Grade 4-age group 13 to 19
M. F. Macnicol, BSc, MChOrth, FRCSEd, Senior Lecturer H. Uprichard, BA, MCSP, Physiotherapist

G. P. Mitchell, MC, FRCSEd, Consultant Orthopaedic Surgeon

Requests for reprints should be sent to Mr M. F. Macnicol
Princess Margaret Rose Orthopaedic Hospital,

Fairmilehead, Edinburgh EH10 7ED,

Scotland.

(1) 1981 British Editorial Society of Bone and Joint Surgery 0301-620X/81/00150048 $\$ 2.00$ 
years; Grade 3-ages 20 to 24 years; Grade 2-ages 25 to 29 years; and Grade 1 -age 30 years or more.

Hip function. The delayed Trendelenburg test (Mitchell 1973) was used to assess the function of the static hip. The test is a sensitive measure of deteriorating stability in the subluxating hip and elicits this deficiency at a stage when the immediate Trendelenburg test still gives a negative result. The range of movement was charted and any loss of the combined range of flexion, abduction and medial rotation noted: a restriction to 130 degrees or less was considered to represent significant stiffening.

Cover. The percentage "cover" of the femoral head by the acetabular roof was calculated using a graph paper technique to measure the overlap on the most recent anteroposterior radiograph. The accuracy of this radiological assessment is in doubt as Benson and Evans (1976) have shown experimentally that even with a 50 per cent medial displacement of the pelvic wall only 1.5 centimetres of extra cover may be achieved if the osteotomy hinges posteriorly at the sciatic notch. The assessment of cover in these cases using the centre-edge angle of Wiberg (1939) has also been criticised as inaccurate (Colton 1972) and it is unlikely that any uniplanar radiograph can indicate its true extent.

\section{RESULTS}

Table I compares the results of the exercise tests for the two groups. The mean maximal walking speed of the patients was $5.9 \pm 0.2$ kilometres per hour, significantly $(P<0.01)$ lower than that of the control group (mean $6.7 \pm 0.1$ kilometres per hour). Cadence was similar between the two groups and hence the difference in walking speed arose from a significant reduction in stride length among the patients. Despite a slower walking speed the mean pulse rate at the end of the walk was significantly higher for this group, indicating a considerably greater effort. There was a significant difference in the stair climbing times between the two groups and again the mean pulse rate of the patients was elevated by a significantly greater degree.

An age-related decline in performance was disclosed (Fig. 1). Above the age of 21 years there was a steady reduction in maximal walking speed compared to the control group and only one patient over the age of 25 years was able to walk at a normal rate. Figure 2 depicts

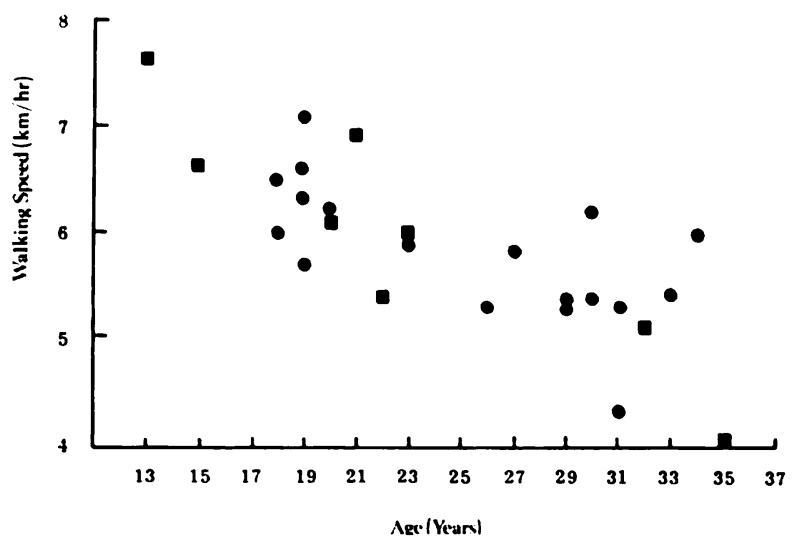

Fig. 1 the relationship between maximal walking speed and the stair climbing time. All the normal subjects walked at six kilometres per hour or faster, with stair climbing times of seven seconds or less. Fourteen of the 26 patients were unable to walk or climb at this rate; of those who could, 83 per cent were 21 years or younger and all had pulse rates which were raised significantly $(P<0.01)$ at the end of the test. The fastest walking speed attained was that of one of the patients, who, at 13 years, was the youngest individual in the study, and who recorded a stair climbing time of five seconds.

Table I. Results of the exercise tests (expressed as mean \pm SEM)

\begin{tabular}{|l|c|c|c|}
\hline & Patients & Controls & Significance * \\
\hline $\begin{array}{l}\text { Maximal walking speed } \\
(\mathrm{km} / \mathrm{hr})\end{array}$ & $5.9 \pm 0.2$ & $6.7 \pm 0.1$ & $P<0.01$ \\
Stride length (cm) & $147 \pm 2.6$ & $164 \pm 2.1$ & $P<0.01$ \\
$\begin{array}{l}\text { Cadence (steps/min) } \\
\begin{array}{l}\text { Pulse rate at finish of walk } \\
\text { (beats/min) }\end{array}\end{array}$ & $134 \pm 1.8$ & $134 \pm 1.7$ & $\mathrm{NS}$ \\
$\begin{array}{l}\text { Stair climbing time (secs) } \\
\begin{array}{l}\text { Pulse rate at finish of climb } \\
\text { (beats/min) }\end{array}\end{array}$ & $126 \pm 3.5$ & $131 \pm 3.5$ & $P<0.01$ \\
\hline
\end{tabular}

*Student's $t$ test for unpaired data: NS=not significant

A reduction in pain to the optimal Grade 4 was achieved in seven patients, with a further 15 obtaining a Grade 3 result; thus 22 patients ( 85 per cent) were significantly relieved of pain after the Chiari osteotomy. Three patients felt no appreciable benefit (Grade 2) and one patient considered her pain to be worse than before operation (Grade 1). The relief of pain and the maximal walking speed were associated. Of the Grade 4 patients, only one walked at a speed of less than six kilometres per hour and she was aged 33 and therefore one of the

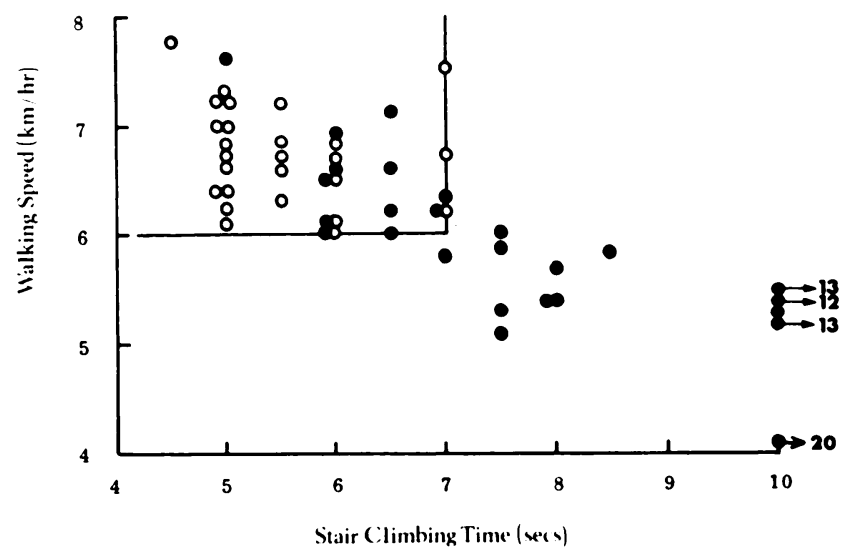

Fig. 2

Figure 1-Linear relationship between decline in maximal walking speed and increase in age in the patients. (•, no contralateral hip dysplasia; $\bullet$, mild contralateral hip dysplasia.) Correlation coefficient $r=-0.848, P<0.001$. Figure $2-$ The relationship between maximal walking speed and the stair climbing time in patients and controls. Normal subjects (o) were all capable of walking speeds of six kilometres per hour or faster, and had stair climbing times of seven seconds or less. Walking speeds and stair climbing times of the patients $(\bullet)$ are correlated in a significant linear fashion: correlation coefficient $r=-0.792, P<0.001$ 
oldest. In contrast, where there was no relief of pain (Grades 1 or 2 ) only one patient walked at over six kilometres per hour, this being a patient aged 20 years who achieved a maximal speed of 6.1 kilometres per hour. The mean maximal walking speeds for pain grades of $4,3,2$ and 1 were $6.2,5.9,5.6$ and 5.3 kilometres per hour respectively.

A significant linear relationship was found between the maximal walking speed and the combined total of the pain grade and the age grade of each patient (Fig. 3), with a regression equation

$$
\frac{\text { Maximal walking speed (kilometres per hour) }}{\text { Pain grade + Age grade }} \approx 1 \text {. }
$$

This indicates the effect that increasing age has upon performance in this group of handicapped women. It also illustrates a clinically useful proportional relationship between function and pain. A further influence upon function was the presence or absence of a positive delayed Trendelenburg sign (Fig. 4) although this did not exert a statistically significant effect.

The total range of movement at the hip and the maximal walking speed did not correlate significantly. Nevertheless only one of the seven patients with less than 130 degrees of combined movement walked at over six kilometres per hour whereas 11 of the 19 patients (58 per cent) with more than this range walked at over six kilometres per hour. A total of 15 of the 26 patients (58 per cent) retained hip flexion of greater than 100 degrees after operation, 21 (81 per cent) had no fixed flexion deformity and 19 (73 per cent) were able to abduct the hip more than 25 degrees. All 26 gained an increase in apparent cover of the femoral head measured radiographically (Figs 5,6 and 7), complete cover being attained in 70 per cent of the patients. Of the remaining 30 per cent all but one had head cover of 85 per cent or more on a current radiograph; the one patient with less satisfactory cover (68 per cent) did not suffer any apparent increase in handicap and the radiographic appearance bore no relationship to exercise capacity or to the relief of pain.

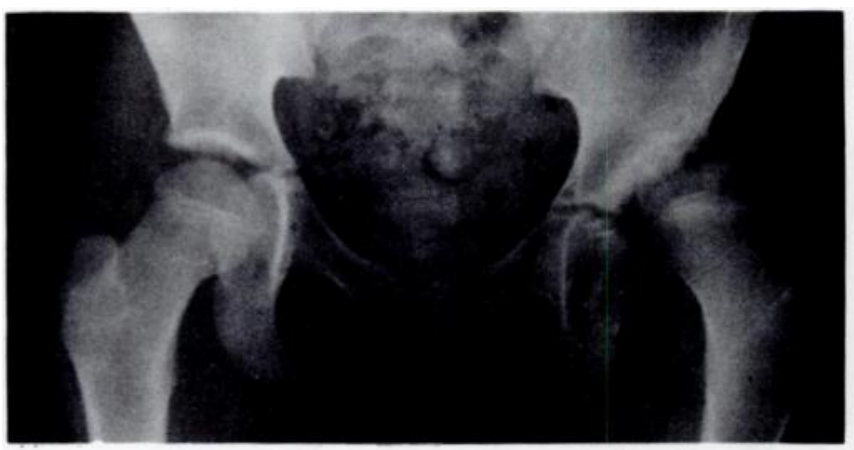

Fig. 5

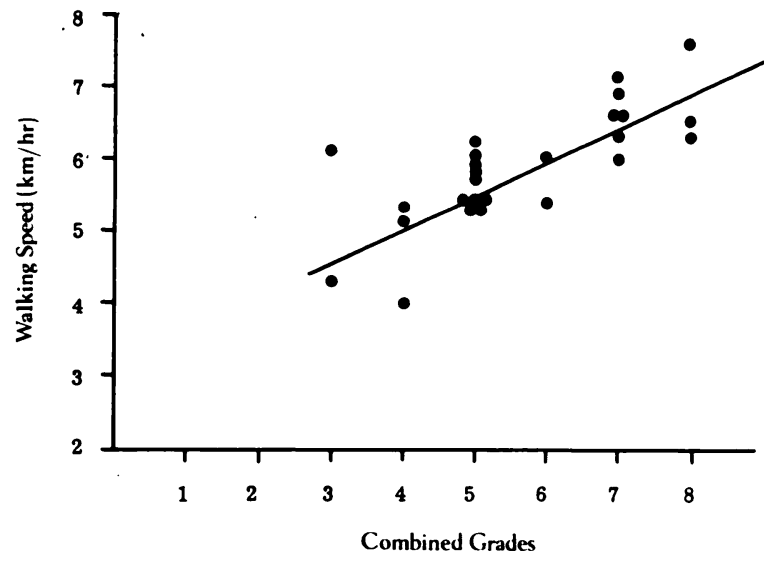

Fig. 3

Maximal walking speed related to a grading scale which combines pain experienced after operation and age. Correlation coefficient $r=+0.761, P<0.001$.

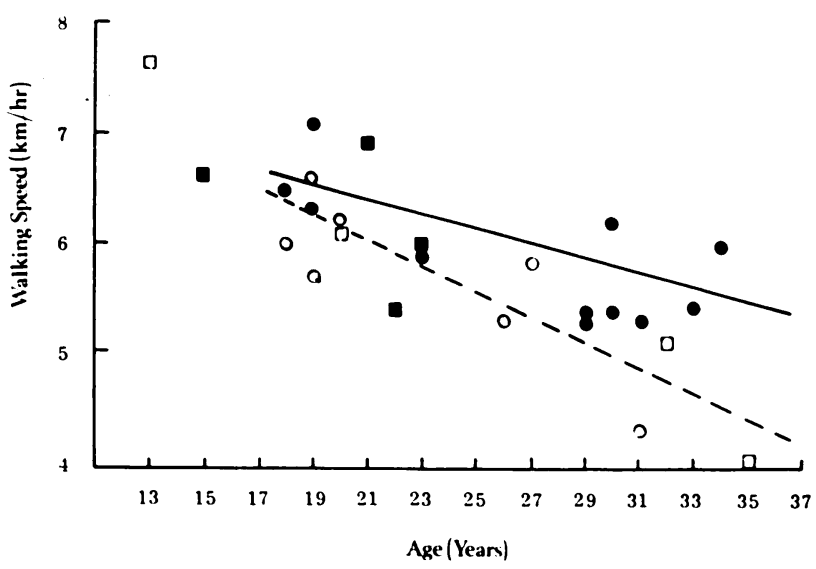

Fig. 4

The influence on maximal walking speed of the presence (solid line) or absence (broken line) of a positive delayed Trendelenburg sign after operation. (॰, positive Trendelenburg sign with no contralateral hip dysplasia; $₫$, positive Trendelenburg sign with mild contralateral hip dysplasia, 0 , negative Trendelenburg sign with no contralateral hip dyplasia; $\square$, negative Trendelenburg sign with mild contralateral hip dysplasia.)

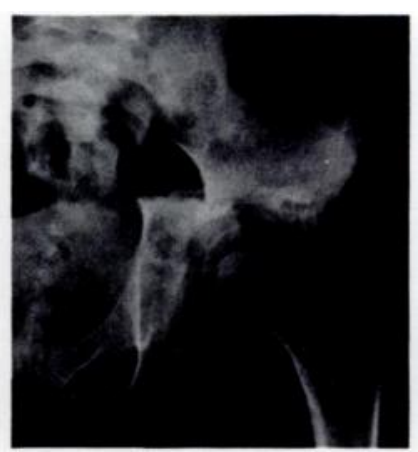

Fig. 6

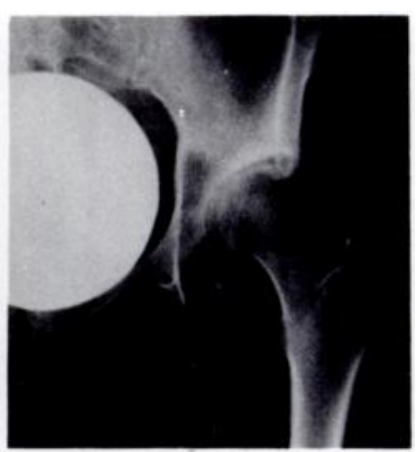

Fig. 7

Figure 5-Radiograph of a 12-year-old patient with a painful subluxating hip. Figure 6-Radiograph six months after operation. Initial fixation employed a Steinmann pin driven down from ilium to ischium, and a hip spica was then applied. Figure 7-Radiograph 10 years after the osteotomy. 


\section{DISCUSSION}

The Chiari pelvic osteotomy is now established as a reasonably successful method of treating the young adult with a subluxated hip secondary to acetabular dysplasia. Although the procedure rarely eliminates pain in the hip completely, a high proportion of patients derive appreciable relief of pain, at least in the early years after operation (Table II). In this review pain was considerably relieved in 85 per cent, making it likely that the results were comparable to other reported series. However, no attempt has been made to contrast these findings with the results of alternative procedures such as the triple innominate osteotomy (Steel 1973), the dial acetabular osteotomy (Eppright 1976) or the double innominate osteotomy (Sutherland 1977).

Table II. Earlier reports of Chiari pelvic osteotomy, showing the proportion of patients with significantly reduced pain

\begin{tabular}{|l|c|}
\hline \multicolumn{1}{|c|}{ Authors } & Per cent \\
\hline Colton 1972 & 71 \\
Mitchell 1974 & 88 \\
Hoffman et al. 1974 & 70 \\
Chiari and Schwagerl 1976 & 75 \\
Lord and Samuel 1977 & 95 \\
\hline
\end{tabular}

Grading of disability is difficult yet important if the results of operations on the hip are to be assessed with precision and comparability. However, Wedge and Wasylenko (1979) have pointed out that, "Most methods of assessing the function of the hip are designed for older patients with osteoarthritis and are heavily weighted to pain". They noted that the younger patient with subluxation scored highly by the grading system of Harris (1969) even if anatomical abnormality was pronounced. They therefore modified the grading to include the results of function in the form of the Trendelenburg test, and thus reduced the influence of pain as the principal determinant of the score. Subluxation was found to lead to problems in the hip that were proportional to the degree of displacement and the age of the patient. The findings in this group of patients confirmed both the importance of assessing dynamic function in addition to pain, and the influence of increasing age upon the capacity for exercise. A clearly defined reduction in maximal walking speed occurred, despite Chiari osteotomy, in patients over the age of 21 years when compared to the performance in the control group. Of the 12 patients capable of exercising at a normal rate (maximal walking speed of six kilometres per hour and over, stair climbing time of seven seconds or less) 10 were aged 21 years or younger. Over the age of 30 years the majority (five out of six) were unable to walk at six kilometres per hour. This trend continues with advancing age: Macnicol et al. (1980) showed that women over the age of 50 with unilateral osteoarthritis of the hip were generally unable to sustain a walking speed of four kilometres per hour.

The Trendelenburg test, particularly in its "delayed" form (Mitchell 1973), is a sensitive indicator of the stability of the hip. Chiari and Schwagerl (1976) observed that the incidence of a positive Trendelenburg sign was reduced from 90 per cent before operation to approximately 40 per cent after pelvic osteotomy but only to $\mathbf{4 8}$ per cent in patients older than nine years. In this series the incidences were 100 per cent before operation and 40 per cent afterwards, using the delayed Trendelenburg test. Hoffman et al. (1974) reported a similar reduction in positive signs, but Schulze and Krämer (1975) only achieved a disappointing incidence of 83 per cent ( 48 per cent "strongly positive", 35 per cent "weakly positive"). The latter authors found that there was no concordance between the radiographic appearances, which were technically satisfactory in most cases, and the outcome of the Trendelenburg test. The radiographs in this series were satisfactory in 96 per cent (femoral head cover of 85 per cent or more) but were of no predictive value in assessing either pain or function. The habit of using a single radiograph to determine the coverage of the femoral head has been called into doubt (Colton 1972; Benson and Evans 1976) and probably only has value if anatomical relationships are grossly abnormal. Furthermore, the total range of hip movement, while an essential part of any clinical examination, has little relation to dynamic function measured by the exercise tests.

The value of exercise tests is that they provide simple, reliable information. The results of operation can be accurately measured and the long-term effects of disease can be monitored. A disadvantage is that they measure the work output of the whole body, so that they lack precision when more than one joint is involved in a pathological process. Nevertheless, tests of performance are a useful adjunct to the standard methods of orthopaedic evaluation and may be satisfactorily conducted in a conventional hospital setting by doctor, physiotherapist or technician.

The authors are indebted to Mrs Evelyn Ward for typing the manuscript, to Miss A. M. Catto for the facilities in the Department of Physiotherapy, and to Mr Michael Devlin for the photographs.

\section{REFERENCES}

Benson MKD, Evans DCJ. The pelvic osteotomy of Chiari: an anatomical study of the hazards and misleading radiographic appearances. $J$ Bone Joint Surg [Br] 1976;58-B:164-8.

Chapchal G. Indications for the various types of pelvic osteotomy. Clin Orthop 1974;98:111-5. 
Chiari K. Ergebnisse mit der Beckenosteotomie als Pfannendachplastik. Z Orthop 1955;87:14-26.

Chiari K. Medial displacement osteotomy of the pelvis. Clin Orthop 1974;98:55-71.

Chiari K, Schwagerl X. L'ostéotomie pelvienne. Rev Chir Orthop 1976;62:560-8.

Chiari K, Endler M, Hackel H. Indications et resultats de l'ostéotomie du bassin selon Chiari dans l'arthrose avancée. Acta Orthop Belg $1978 ; 44: 176-91$

Colton CL. Chiari osteotomy for acetabular dysplasia in young subjects. J Bone Joint Surg [Br] 1972;54-B:578-89.

Eppright RH. Dial osteotomy of the acetabulum. J Bone Joint Surg [Am] 1976;58-A:283.

Harris WH. Traumatic arthritis of the hip after dislocation and acetabular fractures: treatment by mold arthroplasty. $J$ Bone Joint Surg [Am] 1969;51-A:737-55.

Hotman DV, Simmons EH, Barrington TW. The results of the Chiari osteotomy. Clin Orthop 1974;98:162-70.

Kawamura B. The transverse pelvic osteotomy. J Japanese Orthopaedic Society 1959;32:65-9.

Lord G, Samuel P. L'ostéotomie de Chiari chez l'adulte. Chirurgie 1977;103:804-14.

Macnicol MF, McHardy R, Chalmers J. Exercise testing before and after hip arthroplasty. J Bone Joint Surg [Br] 1980;62-B:326-31.

Mitchell GP. The delayed Trendelenburg hip test. In: Orthopaedic Surgery and Traumatology (International Congress Series No 291). Amsterdam: Excerpta Medica, 1973:1113.

Mitchell GP. Chiari medial displacement osteotomy. Clin Orthop 1974;98:146-50.

Pemberton PA. Pericapsular osteotomy of the ilium for treatment of congenital subluxation and dislocation of the hip.J Bone Joint Surg [Am] $1965 ; 47-A: 65-86$.

Salter RB. Innominate osteotomy in the treatment of congenital dislocation and subluxation of the hip. J Bone Joint Surg [Br] $1961 ; 43-B: 518-39$.

Salter RB. Role of innominate osteotomy in the treatment of congenital dislocation and subluxation of the hip in the older child.J Bone Joint Surg $[A m] 1966 ; 48-A: 1413-39$.

Salvati EA, Wilson PD. Treatment of irreducible hip subluxation by Chiari's iliac osteotomy. Clin Orthop 1974;98:151-61.

Schulze H, Krämer J. Ergebnisse der Beckenosteotomie nach Chiari. Z Orthop 1975;113:891-5.

Steel HH. Triple osteotomy of the innominate bone. J Bone Joint Surg [Am] 1973;55-A:343-50.

Sutherland DH. Double innominate osteotomy. J Bone Joint Surg [Am] 1977;59-A:1082-91.

Wedge JH, Wasylenko MJ. The natural history of congenital disease of the hip. J Bone Joint Surg [Br] 1979;61-B:334-8.

Wiberg G. Studies on dysplastic acetabula and congenital subluxation of the hip joint, with special reference to the complication of osteoarthritis. Acta Chir Scand (Suppl) 1939;83: Supplement 58. 